\title{
A Case Study: Industry 4.0 and Human Factors in SMEs
}

\section{Helmut Zsifkovits, Manuel Woschank, and Corina Pacher}

\subsection{Introduction}

In recent years, scientists and practitioners developed a multitude of technologies and technological concepts based on the vision of Industry 4.0 which was conceptualized as a part of an international strategy to increase the productivity and long-term competitiveness of companies by focusing on principles like digitalization, interconnectivity, and autonomization (Zsifkovits and Woschank 2019; Woschank and Zsifkovits 2021). Thereby, a special focus is placed on the continuous development of small- and medium-sized enterprises which are considered as the backbone of the European economy as they are contributing significantly to the local added value (Matt et al. 2020). However, the risks and barriers on the way to a digitalized production and logistics system should not be neglected, especially when it comes to integrating the human being into

H. Zsifkovits $\cdot$ M. Woschank $(\bowtie) \cdot$ C. Pacher

Chair of Industrial Logistics, Montanuniversitaet Leoben, Leoben, Austria e-mail: manuel.woschank@unileoben.ac.at 
reshaped work processes of Industry 4.0-aligned organizations (Dallasega et al. 2019, 2020; Woschank et al. 2020a).

In this context, a multitude of studies reveals that there still seems to be a missing 'digital maturity' regarding the design and implementation of production- and logistics-related processes in SMEs. In a recent study, only $33 \%$ of SMEs working in an industrial environment reported that they have started to implement Industry 4.0-related initiatives. Moreover, most of the participating SMEs consider themselves as relatively underdeveloped in terms of Industry 4.0-strategies by describing themselves as 'digitally aware' or even as 'digital newcomer' while only $10 \%$ of the participating SMEs classify themselves as 'digital orientated'. It should be further noted that in this study, no company would describe itself as a 'digital champion' which means that they have advanced knowledge in the field of Industry 4.0 (Wirtschaftskammer Österreich 2019). In this regard, a study by Fraunhofer IIS confirmed this view by revealing that only $32 \%$ of the participating logistics service providers considered themselves as well developed regarding the maturity for their (transport) logistics processes (Fraunhofer IIS 2017). Nevertheless, 85\% of the participants within an expert survey rate the relevance of the digitalization of the value chain as important or even as highly important (Statista.de 2020) because it will be able to generate a variety of improvement opportunities, as time savings, decreasing susceptibility to errors and failures, physical relief for employees, better service for the end customer, etc. (bitkom 2020b).

Up to now, the digitalization of production and logistics systems is mainly based on the potential usage of the following technologies: warehouse management systems, smart sensors, the usage of tablets and smartphones in logistics operations, electronic freight documents, driverless forklift systems, big data analytics, augmented reality, etc. (bitkom 2020a). Thereby, the main barriers regarding the implementation of Industry 4.0 strategies can be summarized as high investment costs, data protection challenges, lack of knowledge, the complexity of the subject itself, the vulnerability of systems to failures, etc. (bitkom 2020c; Wirtschaftskammer Österreich 2019). 
However, a multitude of studies stresses the importance of the human workforce for the successful implementation of Industry 4.0 technologies and technological concepts (Creditreform 2019). In the regard, the study of Hobscheidt et al. focused on the development of risk-optimized implementation paths for Industry 4.0 based on socio-technical patterns. Thereby, they state that the dimensions of humans, technology, and organization interact interdependently so that the risks and their effects become almost unmanageable. Therefore, structured tools, e.g., riskoptimized socio-technical implementation paths or implementation roadmaps, are absolutely necessary (Hobscheidt et al. 2020). Vuksanović Herceg et al. introduced an exploratory research study where they analyzed the most important driving forces and implementation barriers of companies in Serbia. Surprisingly, the participants did not see human resources as the driving force behind the implementation, but rather as a barrier when they lack the necessary competencies and skills (Vuksanović Herceg et al. 2020). Cresnar et al. focused on the usage of management tools to speed up the implementation of Industry 4.0. The empirical results tendentially revealed a significant correlation between the usage of various management tools (e.g., Balanced Scorecard, Six Sigma, TQM, etc.) and the Industry 4.0 readiness in manufacturing organizations (Črešnar et al. 2020).

In this chapter, the authors investigate a set of requirements for the successful implementation of Industry 4.0 in SMEs that are directly, or at least indirectly, related to human factors. After a structured analysis of the recent literature on human factors, the authors outline current knowledge regarding critical success factors of learning processes and discuss the transformation process toward a learning-orientated culture in manufacturing enterprises and describe a case where the role of human factor within an Industry 4.0 approach is analyzed more in detail.

\subsection{Problem Formulation}

In this subsection, the authors analyze a data set dealing with possible barriers to Industry 4.0 concepts in smart logistics from the perspective of human factors. This can be seen as the starting point of the subsequent 
investigation regarding the role of human beings in the digital transformation process in manufacturing enterprises. The primary data is based on theoretical research which has been systematically extended by semistructured expert interviews in international workshops with scientists and practitioners and finally evaluated by using a large-scale survey.

In a global research study, Dallasega et al. exploratively evaluated the requirements for the implementation of Industry 4.0 in SMEs by focusing on the area of smart logistics. Based on the Grounded Theory, the research team conducted a total of six workshops with 37 SMEs and 67 experts in Italy, Austria, the USA, and Thailand leading to a total of 548 statements as an outcome of the subsequent content analysis. The statements were further aggregated to a total of 16 items within the three clusters of (1) 'smart and lean x-to-order supply chains' (SAL), (2) 'intelligent logistics through ICS and CPS' (ICT), and (3) 'smart and automated logistics vehicles' (AUT) (Dallasega et al. 2019, 2020). In a follow-up survey, the items were ranked by logistics and/or supply chain professionals in Europe regarding the importance by using a Likert scale ranging from $1=$ not important to $5=$ very important. Therefore, a total sample of 9,032 logistics and/or supply chain managers was contacted via e-mail by using an online-based survey tool leading to 71 valid answers and a total response rate of $0.78 \%$.

In the next step, the items were evaluated by an expert team, consisting of three independent researchers, regarding their relevance in terms of human factors by using the coding $1=$ highly pertinent, $2=$ moderately pertinent, and $3=$ not pertinent. The results are presented in Table 8.1.

The qualitative content analysis revealed that most requirements for the implementation of Industry 4.0 in SMEs are directly, or at least indirectly, related to human factors. 'The importance of specific work instructions for the collaboration throughout the supply chain by using ICT' was ranked as the most important one, followed by 'the training and further qualification of employees focusing on state-of-the-art software and data analysis tools'.

Furthermore, it will be important to train the human workforce regarding tools and methods which will allow an identification and avoidance of material flow breaks throughout the supply chain' as was as in the usage of advanced planning and control systems (PPC) that 
Table 8.1 Human-factor-related success factors

\begin{tabular}{|c|c|c|c|c|}
\hline Code & Item & Mean & $\begin{array}{l}\text { STD } \\
\text { DEV }\end{array}$ & Pertinance \\
\hline SAL6 & $\begin{array}{l}\text { The implementation of specific work } \\
\text { instructions for collaboration } \\
\text { throughout the supply chain by } \\
\text { using ICT }\end{array}$ & 3.84 & 0.84 & 1 \\
\hline SAL5 & $\begin{array}{l}\text { The training and further qualification } \\
\text { of employees focusing on } \\
\text { state-of-the-art software and data } \\
\text { analysis tools }\end{array}$ & 3.84 & 0.93 & 1 \\
\hline SAL1 & $\begin{array}{l}\text { The identification and avoidance of } \\
\text { material flow breaks throughout } \\
\text { the supply chain }\end{array}$ & 3.93 & 0.86 & 2 \\
\hline SAL4 & $\begin{array}{l}\text { The usage of advanced planning and } \\
\text { control systems (PPC) that allow } \\
\text { forecasting rapidly demand changes }\end{array}$ & 3.86 & 0.93 & 2 \\
\hline ICT6 & $\begin{array}{l}\text { The usage of decision support } \\
\text { systems for planning and } \\
\text { controlling logistics (e.g., for } \\
\text { supplier selection decisions) }\end{array}$ & 3.84 & 0.88 & 2 \\
\hline ICT4 & $\begin{array}{l}\text { The limitation of data access to } \\
\text { different stakeholders in the supply } \\
\text { chain }\end{array}$ & 3.80 & 0.87 & 2 \\
\hline SAL2 & $\begin{array}{l}\text { The on-demand (Just-in-Time) } \\
\text { production and delivery of products } \\
\text { to the customers }\end{array}$ & 3.91 & 0.90 & 3 \\
\hline SAL3 & $\begin{array}{l}\text { The availability of real-time order } \\
\text { information regarding the status of } \\
\text { production and shipping } \\
\text { throughout the supply chain }\end{array}$ & 3.90 & 0.80 & 3 \\
\hline ICT5 & $\begin{array}{l}\text { The alignment of ERP/database } \\
\text { systems throughout the supply } \\
\text { chain }\end{array}$ & 3.87 & 0.87 & 3 \\
\hline ICT3 & $\begin{array}{l}\text { The transparency of inventory levels } \\
\text { and storage locations throughout } \\
\text { the supply chain }\end{array}$ & 3.84 & 0.95 & 3 \\
\hline ICT2 & $\begin{array}{l}\text { The digital tracking of products } \\
\text { throughout the supply chain }\end{array}$ & 3.83 & 0.92 & 3 \\
\hline ICT7 & $\begin{array}{l}\text { The ensurance of data security } \\
\text { throughout the supply chain }\end{array}$ & 3.83 & 0.81 & 3 \\
\hline
\end{tabular}


Table 8.1 (continued)

\begin{tabular}{lllll}
\hline Code & Item & Mean & $\begin{array}{l}\text { STD } \\
\text { DEV }\end{array}$ & Pertinance \\
\hline ICT1 & $\begin{array}{l}\text { The digital connection of customers } \\
\text { and suppliers for improved } \\
\text { collaboration throughout the supply } \\
\text { chain }\end{array}$ & 3.83 & 0.95 & 3 \\
AUT1 & $\begin{array}{c}\text { The usage of automated ordering } \\
\text { systems }\end{array}$ & 3.68 & 0.94 & 3 \\
AUT3 & $\begin{array}{l}\text { The self-control of warehousing } \\
\text { processes (autonomous processes) } \\
\text { The self-control of material flow } \\
\text { processes (autonomous processes) }\end{array}$ & 3.68 & 0.91 & 3 \\
AUT2 & 0.65 & 3 \\
\hline
\end{tabular}

allow forecasting rapidly demand changes'. The increasing complexity of logistics processes generally requires support in cognitive activities, for example by 'the usage of decision support systems for planning and controlling logistics (e.g., for supplier selection decisions)'. Furthermore, employees should receive ongoing training in data security to adequately address this important subject. This also includes 'the limitation of data access to different stakeholders in the supply chain'.

\subsection{Related Work}

In this subsection, the authors review the recent literature on human factors for the successful implementation of Industry 4.0 strategies in smart logistics. Therefore, the keywords 'human factor', 'human capital', 'human integration', or 'human*' were used in combination with the keywords 'industrial logistics', 'smart logistics', or 'logistics 4.0'. We focused on the research areas of 'engineering' and 'business management and accounting' and only used studies were written in the English language without a restriction regarding the type of study within the last ten years by using the database Scopus as the main source for our literature analysis. An additional analysis in similar databases (e.g., Web of Science, Science Direct, Emerald, etc.) did not lead to significant differences in the resulting research studies (Woschank et al. 2020b). 
Based on the overall research strategy, the search string was formulated as follows: TITLE-ABS-KEY ('human factor' OR 'human capital' OR 'human integration' OR 'human*') AND TITLE-ABS-KEY ('industrial logistics' OR 'smart logistics' OR 'logistics 4.0') AND (LIMIT-TO ( SUBJAREA, 'ENGI') OR LIMIT-TO (SUBJAREA, 'BUSI')) AND (LIMIT-TO (LANGUAGE, 'English')). The characteristics of our literature analysis are summarized in Table 8.2.

In the first step, the literature review resulted in a total of 31 identified studies for the initial quantitative analyses. Therefore, the descriptive results of the identified will be presented in the next paragraphs. Figure 8.1 shows the development of the research studies in the time frame from 2010 to 2020.

In general, there is a strong upward trend in the number of identified studies in the time frame from 2010 to 2020. In detail, $6.25 \%$ were published in 2013, 3.13\% were published in 2014, 3.13\% were published in 2016, 9.38\% were published in 2017, $21.88 \%$ were published in 2018, 9.38\% were published in 2019 while most the studies (43.75\%) were published 2020.

From the type of study, $48.39 \%$ of the identified studies were published as conference proceedings, $38.71 \%$ are articles, $6.45 \%$ are books, and $6.45 \%$ are published as reviews. The results are displayed in Fig. 8.2.

As indicated in Fig. 8.2, most of the publications were either published as a conference paper or as an article. Additional analysis revealed that

Table 8.2 Characteristics of the literature analysis

\begin{tabular}{lllll}
\hline Keywords (1) & Keywords (2) & Language & Time frame $^{\mathrm{a}}$ & $\begin{array}{c}\text { Type of } \\
\text { Study }^{\mathrm{a}}\end{array}$ \\
\hline Human Factor & $\begin{array}{c}\text { Industrial } \\
\text { Logistics }\end{array}$ & - & $2010-2020$ & - \\
Human Capital & $\begin{array}{c}\text { Smart } \\
\text { Logistics } \\
\text { Logistics 4.0 }\end{array}$ & English & - & - \\
$\begin{array}{l}\text { Human } \\
\text { Integration }\end{array}$ & - & - & - & - \\
Human* & - & - & - & - \\
- & - & - & - & - \\
\hline
\end{tabular}

${ }^{\mathrm{a}}$ No further restrictions were defined 


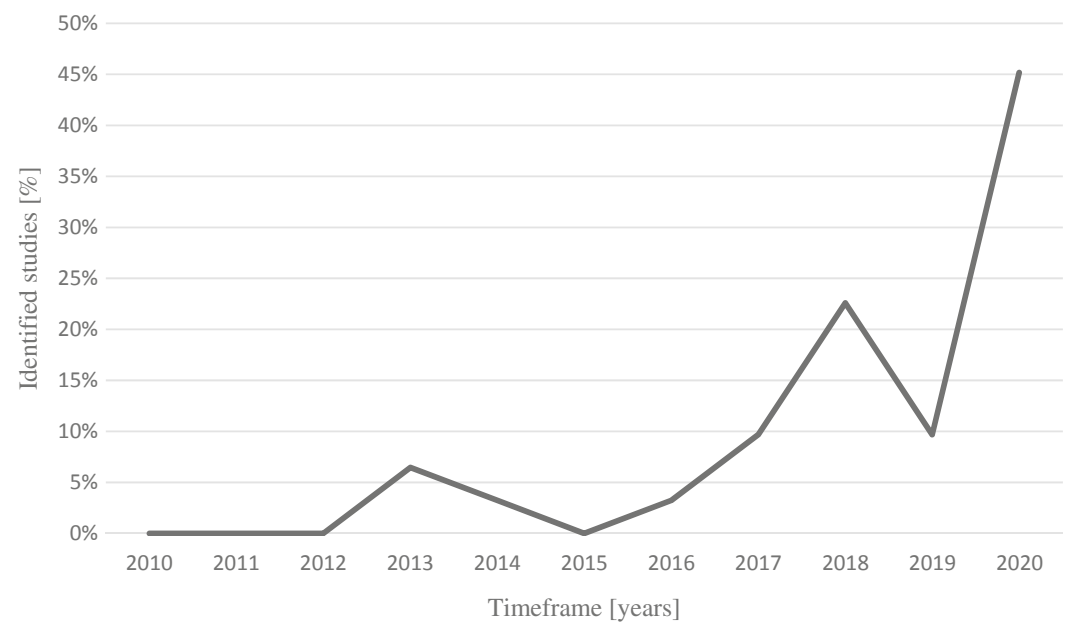

Fig. 8.1 Development of the relevant research studies from 2010 to 2020

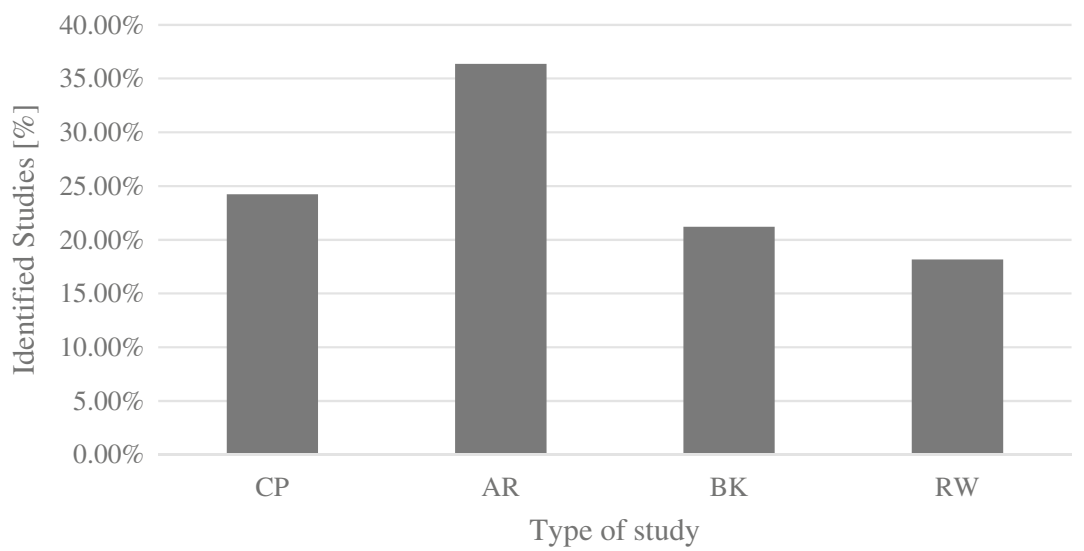

Fig. 8.2 Classification of the relevant research studies per type of study: Conference papers (CP), articles (AR), books (BK), and reviews (RW)

most of the identified studies $(70.97 \%)$ were published in a wide variety of media and, therefore, assigned to the category 'others', $19.35 \%$ were published in 'Advances in Intelligent Systems and Computing' (19.35\%), 
and $9.68 \%$ were published in 'Procedia Manufacturing'. Therefore, Table 8.3 displays the main sources of the identified studies.

Figure 8.3 provides an overview of the identified research collaborations.

From the point of research collaborations, $3.23 \%$ of the identified studies were written by one author, $12.90 \%$ of the identified studies were written by two authors, $32.26 \%$ of the identified studies were written by three authors, $38.71 \%$ of the identified studies were written by four authors, $9.68 \%$ of the identified studies were written by five authors, and $3.23 \%$ of the identified studies were written by seven authors.

Figure 8.4 displays the analysis of research subject-related keywords. Regarding the research of human factors in Industry 4.0, the most important related author keywords are 'Internet of Things', 'Human (integration)', 'Robot (integration)', '(Teaching) and Learning', and 'Mobility and Technology' and the most important index keywords are

Table 8.3 Distribution of the identified studies

\begin{tabular}{llc}
\hline Source & Records (\#) & Records (\%) \\
\hline Advances in Intelligent Systems and Computing & 6 & 19.35 \\
Procedia Manufacturing & 3 & 9.68 \\
Others & 22 & 70.97 \\
\hline
\end{tabular}

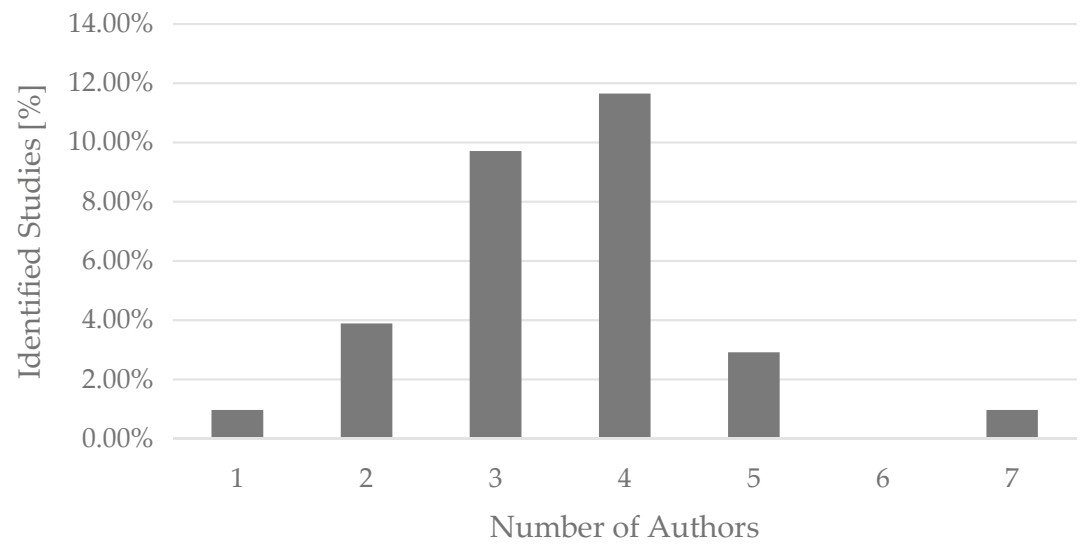

Fig. 8.3 Overview of the identified research collaborations 


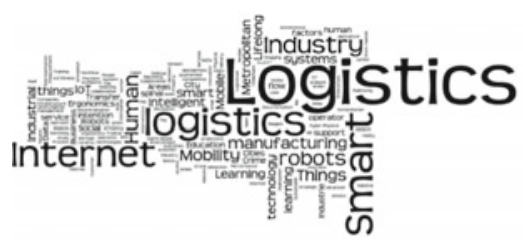

Internet of Things: \#1

Human (Integration): \#2

Robot (Integration): \#3

(Teaching) and Learning: \#4

Mobility and Technology: \#5

Author Keywords

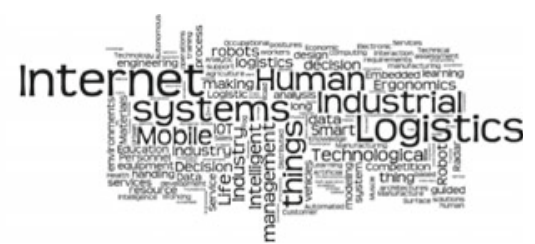

Internet of Things: \#1

Human (integration): \#2

(Smart) Systems: \#3

Decision (Making/Support):\#4

(Big) Data (Analysis): \#5

Index Keywords

Fig. 8.4 Analysis of keywords

'Internet of Things'. 'Human (Integration)', '(Smart) Systems', 'Decision (Making/Support)', and '(Big) Data (Analysis)'.

In a second step, the abstracts of the identified studies were qualitatively analyzed by the research team and by three additional reviewers and coded with $1=$ highly pertinent, $2=$ moderately pertinent, and $3=$ not pertinent for subsequent full-text analysis. Thereby, studies without significant differences were directly included or excluded in/from the research process. Studies with significant differences were reevaluated by the research team to get unambiguous research results (Woschank et al. 2020b). Overall, the research process resulted in $25.81 \%$ highly pertinent studies, $35.48 \%$ moderately pertinent studies, and $38.71 \%$ not pertinent studies. Consequently, the content of the highly pertinent studies will be briefly summarized and analyzed within the new paragraphs.

Cimini et al. investigated the impact of the introduction of Industry 4.0 technologies on human factors in logistics operations. Whether these technologies are more likely to replace humans or aim to support them is discussed in more detail. The relationships were summarized in a human factor matrix and exploratively tested in a longitudinal case study. As a result, the identified technologies can be used to support stressful and repetitive physical tasks and complex cognitive tasks, as well. In general, the evolution is more toward assistance rather than to a replacement of the human workforce (Cimini et al. 2020). 
Winkelhaus and Grosse conducted a systematic literature review for the development of a new logistics system framework. By reviewing 114 articles the authors conceptualized a framework that combines external triggers, main technological innovations, impacts of human interactions, and logistics tasks based on the technologies of the Internet of Things, cyber-physical systems, Big Data, cloud computing, mobilebased systems, social media-based systems, etc. As an outcome, the authors postulate that the human-centric view was not discussed intensively yet. Future research should focus on the design of logistics systems from a human-centric point of view by focusing on topics, e.g., worker shortage, demographic changes, systematic skill development, new ways of learning, and the digital transformation based on the capabilities of the employees (Winkelhaus and Grosse 2020).

Schmidtke et al. evaluated the technical potentials and challenges within internal logistics 4.0 by discussing the future role of human beings in the industrial working environment. They concluded that humans never will be completely replaced within the processes of industrial production. Science and industry must develop working environments that allow the collaboration between humans and assistance systems (Schmidtke et al. 2018).

Delfmann et al. demonstrated why logistics operations will play an even increasingly central role in the future and, thereby, state that logistics must be a crucial element within the Industry 4.0 implementation strategies. Furthermore, eleven central research questions are presented which are of high importance for the entire research community. Thereby, question nine focuses on the interaction of humans and autonomous machines as equal partners in socio-technical systems. Moreover, question eleven is addressed toward the systematic development of qualifications and competencies for Industry 4.0 (Delfmann et al. 2018).

Wrobel-Lachowska et al. stated that because highly qualified workers will be needed in the logistics sector in the future, the fact arises that the educational process must be adapted. Selected logistics companies and universities were studied to conduct and present an analysis of the challenges for logistics education. They concluded that universities should redesign their courses by implementing modern learning 
methods, change the role from a teacher to a mentor, reinforce cooperation, and shape competencies based on the needs of the industry (Wrobel-Lachowska et al. 2019).

Beham et al. focused on the optimization of slab logistics processes in the steel industry. They further state that automated decision support systems are frequently not accepted by human operators. They developed a cooperative system where human input is required to confirm the status of the material which should be used to reduce data errors, human errors, and the breakdown of machines and vehicles (Beham et al. 2020).

Tran-Dang et al. investigated the role of the Internet of Things for logistics. Thereby, they stated that is important to combine human knowledge with machines that support decision-making. However, besides technical challenges, the coordination and harmonization of control and management policies and regulations are identified as further key success factors (Tran-Dang et al. 2020).

\subsection{Learning and Learning Culture}

The implementation of Industry 4.0 technologies and concepts in companies entails both a transformation of production processes and the changed work and learning processes for employees. Thereby, it is important to notice that the increasing complexity and the associated changes in technical work processes require operational learning processes for all employees (Ullrich et al. 2018).

The work of the future will be more flexible, more mobile, and more digitally networked. This is a result of the current transformation processes toward digitization affecting all areas of human life. However, humans will not be replaceable by technologies or machines in the future. In this regard, Dengler and Matthes forecast that the current number of $40 \%$ of all employees in jobs with low substitutability potential will decrease a maximum of $30 \%$ employment level through automation. Conversely, this study makes clear that the human workforce will continue to be regarded as an essential component in global value chains. It seems to be obvious that an ongoing specialization requires adapted operational or organizational learning processes. However, these 
processes cannot be viewed in isolation, but they must be considered as part of organizational development (Dengler and Matthes 2015; Zehnder 2014).

Consequently, it becomes clear that companies are increasingly required to design, manage, and integrate learning processes and learning environments into their organizations to be able to prepare employees based on the changing fields of work and tasks. Organizations need to transform learning organizations and employees also need to acquire lifelong knowledge. For these reasons, learning processes during the entire life are considered enormously important. The principle of lifelong learning (LLL) affects all dimensions of society and makes a significant contribution to maintaining and increasing workability and, therefore, contributes to the increase of competitiveness. However, this raises the question of to which the extent the respective organization responds to the changing environmental requirements in a learning manner by planning and implementing individual, collective, and organizational learning processes. In this context, Franz states that the process of learning in organizations is essentially dependent on the communication patterns within and between the participants. Therefore, the authors will define the term 'learning processes' and provide implications for organizations regarding the implementation of learning processes and suitable learning environments, as well (Franz 2016).

Learning takes place always and everywhere and includes all areas of daily life. Through the permanent intake of information and everyday experiences, respectively, an expansion of the human scope of action and habitus takes place. Based on this learning process, an ongoing change is generated and serves as a foundation for further learning activities. In general, the learning process by itself can be divided into three phases. In the first phase, which is also referred to as 'acquisition', new knowledge is generated. The incorporation of new knowledge is defined as 'perception'. The knowledge is then subsequently incorporated into the next phase. 'Retention' comprises the second phase. During this process, what has been learned is stored in the memory as a reminder. In the third learning phase, the so-called reproduction, the application of the stored knowledge and the learned competences take place (Geller 1996). 
Hereby, the principle of lifelong learning describes the expectation to deal with learning and educational processes in the entire course of life, due to social changes of the knowledge society, such as industrialization 4.0 or the half-life of knowledge and the associated need for action. The European Union defines LLL as 'any purposeful learning activity that serves a continuous improvement of knowledge, skills, and competences'. Accordingly, LLL is both an opportunity and a challenge for all people. The overall process of learning across the lifespan takes place in different following dimensions: (1) Temporal: The focus is on the entire life course, no longer limited to the stages of childhood and adolescence or young adulthood. Learning and educational trajectories must be considered and considered across the lifespan; (2) Content: LLL refers to all learning processes inside and outside educational institutions. Thus, learning takes place not only in educational institutions but also in other places of learning and in all diverse forms; and (3) Spatially: LLL no longer involves the mere acquisition of cultural goods or professional competencies but encompasses all kinds of topics and subjects as well as the development of skills and the change of self-perception and world perception (Hof 2013).

Learning processes need to be investigated from a time- and processorientated perspective. Learning is a lifelong process, not just the short-term acquisition of new levels of knowledge, but the longer-term confrontation with observations from the world. Learning is integrated into the daily life of the individual learner and, therefore, also into company processes. Therefore, a special emphasis should be placed on human beings as capital for a company as well as for the entire society. Consequently, the human workforce is considered as an 'individual educational subject' including their specific life situations and individual as well as collective goal settings. The LLL approach further leads to a delimitation of learning boundaries and, therefore, to a multitude of massive changes at the institutional level. Organizations should not only focus on the design of appropriate learning environments and learning formats, but also on the constitution of appropriate institutional frameworks. Therefore, in any case, networking, communication, and cooperation are essential at all organizational levels for the integration of individual and collective learning experiences. Human beings acquire 
knowledge on different levels during their lives. Three specific forms of learning can be divided into (1) informal, (2) formal, and (3) non-formal learning processes. Informal learning takes mainly place in everyday life and mostly by unconscious learning experiences. In educational institutions, formal learning is acquired through predefined curricula and finally confirmed by a formal qualification. Non-formal learning usually takes place within courses, further educational measures, or seminars and is not characterized by a certificate. In the context of learning and educational processes, these forms of learning are interdependent meaning that no precise separation can be made. Learning processes are furthermore dependent on the form of organization which can be divided into the individual, collective, and organizational processes, whereby again the boundaries may overlap (Woschank and Pacher 2020a, b, c, d).

In general, there is no precise definition or theory regarding the concept of individual learning processes. The process of individual learning includes the independent and self-controlled information intake and the subsequent processing of information. The self-controlled learning process is based on two essential prerequisites. On the one hand, the learner must be capable of autonomous learning. This is the case if the learner can decide on the topics as well as on the methods on his responsibility. On the other hand, the learning process requires the necessary willingness to learn on the part of the individual (Eggers 2007). Autonomous learning takes place primarily in private settings and, therefore, mostly outside educational institutions (Haefner 1980). This form of learning is becoming increasingly important today regarding learning over the entire lifespan since we live in a knowledge society and permanent education is essential for maintaining and expanding human working abilities which should lead to increased competitiveness of the society.

Collective learning processes take place in form of interactions between subjects, respectively, in a social group. According to Miller, an individual can only learn something new, if learning processes take place in an integrated manner based on an interaction with a person or group. Thereby, the individual ability to learn of all persons involved is considered as a prerequisite. Collective learning processes can generally be defined as the sum of a wide variety of individual processes 
allowing 'a universal antigenic sequence of awareness regarding the connection between logic, rational reasoning and a moral view of the word produced by the individual in the course a lifelong process of development and education' (Miller 1986). Asymmetric levels of information within a group can be considered as a starting point for collective learning processing. Thereby, the exchange of information enables collective processes and can subsequently also lead to a change in values regarding the organization and, therefore, affect the entire organizational culture (Miller 1986).

Organizational collective learning processes, often also known as organizational learning processes, describe the learning at the workplace and/or in organizations. In this regard, Probst and Naujoks understand organizational learning as 'the ability of an institution to discover mistakes, to correct them, and to change the organizational values and knowledge base in a way that problem-solving abilities and capabilities for action are generated' (Probst and Naujoks 1993).

Within organizational learning processes, findings from individual learning processes are mostly transferred to organizations (Hodel and Geißler 1998). This process takes place in two stages. First, learning consists of the acquisition of elements to understand a system. In the second stage, collectivization processes take place, which subsequently manifests organizational learning (Hodel and Geißler 1998). All participants are substantially involved in educational success, like superiors, coworkers, or also the training offerors and/or the persons responsible for the training. Organizational learning is thus dependent on a variety of success factors, such as trust, appreciation, various or communication patterns. For learning settings in organizations, Treml distinguishes between (1) functional, (2) extensional, and (3) intentional forms of learning and communication (Treml 2000).

In the functional setting, learning takes place implicitly, e.g., incidentally, in everyday work. This implicit learning and the associated knowledge are usually generated unconsciously through imitation, in the sense of Jean Piaget's process of assimilation. However, this exchange can only take place if there is a certain degree of trust among the members or within the team. Trust correlates with the climate within a group. Accordingly, it becomes clear that learning in organizations is strongly 
influenced by the working climate. A better climate and appreciation among each other will consequently lead to higher learning success within a team. In contrast to this, an unsatisfactory working climate will most likely lead to both moderate learning processes and deficits in professional competencies (Zehnder 2014). Moreover, extensional learning includes, for example, the intended establishment of interdisciplinary working groups within business organizations to provide space for exchange and a potential change of individual perspectives. The extensional form of learning and communication aims at a proactive interaction of different (professional) perspectives to promote joint learning and collective development processes. Furthermore, intentional forms of learning must be developed as formal learning processes in organizations, such as quality development processes like strategy meetings (Franz 2016).

In conclusion, it can be stated that the establishment of a learning culture in organizations is indispensable to be able to professionally adapt the human workforce to the permanently changing working environment. Collective learning processes are influenced by a multitude of determinants, e.g., the team climate, feelings, individual motives, and appreciation. It is important to notice that the management is responsible for the shaping of the corporate culture and thus also the associated learning culture. Management must create the necessary conditions for successful learning in and as an organization and involve all participants in this cyclical processes. Within the development process, appreciation and recognition of the people involved and their activities are of essential importance. Recognition creates a sense of belonging to the respective organization and, therefore, contributes significantly to a common commitment.

Within the framework of organizational learning processes, the cooperation of interdisciplinary teams can be promoted through targeted educational events that aim to generate joint learning and, subsequently, joint knowledge. Therefore, potential measures could include discussions, joint projects, courses, or further training measures. Knowledge transfer and (informal) exchange should be promoted, since, in addition to technical competencies, transversal competencies such as communication skills, problem-solving skills, teamwork skills, and creativity will 
be of essential importance in the future. The organizational learning processes should therefore aim at a holistic understanding of education and support the cooperation between the organizational development team, all affected departments, and human resource management. In this way will it be possible to prepare the workforce for the changing working environment and equip the human workforce with the necessary competencies, thus generating an interdisciplinary learning and communication culture in business organizations.

\subsection{A Case of Human Factors in Implementing New Technology}

The challenges of introducing Industry 4.0 in an organization are not purely technical. The effort to change processes through digital technologies in a traditional work environment is often met with strong resistance from the humans affected by the change. When implementing new processes, there are often strong mental barriers from people that have been doing the work in a certain manner over the years. Technology is an enabler for innovation, can potentially facilitate or support manual tasks, but it is also seen as a threat, making a human's work and mindless essential, and machines can even replace human work.

To make Industry 4.0 a success, in addition to technological challenges, organizational adaptations are required, and a change in mindsets. The adoption of operating procedures, technologies, and systems as part of the Industry 4.0 concept relies on the human factor. Human workers often have goals that are quite different from those of the organization. They are aiming to enter and remain in the market, build their career, and obtain equitative wages, stability, intellectual growth, learning and/or professional achievement. Companies rather seek the best possible human performance to increase productivity (Silva et al. 2019). Neglecting the human factor will inevitably fail.

Using the case of one machining services company, the implementation scenario is described, with the challenges and barriers met, and the steps required to ensure an effective implementation of new technology. 


\subsubsection{The Objective of Investigation: The Company 'Precision Machine Products, Inc.' (PMP)}

The company was founded 45 years ago, with its operations in a rural, small-town environment. They are industry leaders in CNC machining, with machines including a wide range of brands and dimensions. Their capabilities include drilling, deburring, grinding, milling, turning, contour milling, broaching, thread cutting, slotting, tapping, band sawing, and tube fabrication. Materials worked with include different qualities of steel, aluminum, brass, copper, and plastics. They are capable of working with extremely low tolerances.

Value-added services include CAD design, CAM programming, assembly, laser welding, laser engraving, inventory management, and outsourced finishing services (grinding, plating, heat treating, and anodizing). Industries served to include industrial automation, medical, aerospace, agricultural, electronic, robotics, oil and gas, hardware, plumbing, optics, among others. PMP is a strong and reliable partner to its customers, also specializing in secondary operations, providing JIT, KANBAN, and emergency services.

They have been facing stronger competitive pressure in recent years, with new entrants on the market. These are mostly young companies, driven by innovative technologies. A high level of automation gives these enterprises much flexibility and cost advantage. A narrow specialization in niche products opens them new markets, making them a competitor to PMP.

The management decided to go for a progressive strategy, meeting the challenges by innovating the entire company. The goals to achieve were defined as follows:

- Foster digital technologies (Industry 4.0)

- Improve flexibility of operations

- Make processes more robust

- Increase visibility within the production processes

Some limitations had to be observed. One of these was the budget. PMP at that point could not invest in machines and technology as they wished. 
So, most of the equipment had to stay in place, being slowly replaced over the next years. Also, management did not have intentions to make major changes to the workforce. Most of the workers came from the town and had long been employed by PMP, some of them in the second generation.

PMP hired a Continuous Improvement Manager to drive the process. Serge was a brilliant, ambitious guy, with long experience in the automotive industry. He had been managing several major technology projects, including workplace automation, automated warehouses, and robotics.

Next, the search for a technology partner started. What PMP was expecting to realize over the next years was rather Industry 3.5 than 4.0 in terms of technology maturity. Keeping this in mind they needed a partner that could provide turnkey products that integrated seamlessly with how PMP as a manufacturer worked today. Most of their machines and equipment were to stay in operation for the years to come. So, this would have to be an evolutionary approach, making small improvement steps instead of huge disruptive changes.

DataFusion, Inc. is an innovative startup company, founded by two striving entrepreneurs a few years ago. They bring advanced enterprise data skills, have a track record of commercializing technology, and have held executive leadership positions at several startups.

DataFusion started on the premise that Industry 4.0 would require turnkey solutions that integrate seamlessly with how manufacturers work today. Their software platform is an information system for shop floor performance. It fuses data from all machines into a production scoring system, monitoring overall equipment efficiency (OEE) and shop floor productivity in real-time.

Real-time production scoring automatically tracks specific jobs on the machines and establishes a benchmark of efficient production. Performance vs. the benchmark is monitored, focusing the operators' attention on improving the lower scores.

PMP is a key customer for DataFusion, as a startup, they are still quite new on the market and eager to attract some major accounts for strengthening their market presence and further development of solutions. 


\subsubsection{The Project}

PMP at the time of project start had around 100 machines on the shop floor, of various brands. There are 4-5 different classes of machines. Most of the machines run in one shift. Some of them are in two-shift operation, mainly because of long set-up times. These are assigned to one large customer. In the second shift, a small number of staff are assigned.

Set-up is a problem creating bottlenecks in using the capacity. Small production batches or one-piece flow, therefore, it is not realistic. There are some efforts to work on set-up times to improve and get more flexibility.

Most of the machines could be easily connected to the DataFusion platform, using their data collection stations. These support most major machine tool brands. Data transfer is done by WIFI into the cloud-based platform. Around 20 of the machines were not suitable for integration, due to lacking interfaces.

The data integration was achieved in a very short time. The realtime production scoring was up and running within a few days. Beyond machine status, utilization, and OEE numbers, the system enabled benchmarking machines. Workstations with a low performance can be easily identified and selected for focusing on productivity improvement efforts.

The achievements of the project are quite promising. Integration of machine data into one platform offers opportunities to better control performance, establish benchmarks, and detect bottlenecks and problems. The management of visibility is critical for the adoption and success of the system.

\subsubsection{The Human Factor}

PMP is a family business in the third generation. This is characteristic of the company culture. Workers tell you why something does not work, they have always done it the same way. It is very difficult to change the mindset. 
Serge, the Continuous Improvement Manager, guided us through the facility. He is passionate about his work, sees a large potential for improvement of operations, strengthening PMP's position in the competitive market.

The majority of working processes could be automated, but Industry 4.0 is intended to improve human work and not replace people. The workers are still to be convinced, though. They are more difficult to handle than the machines, Serge said.

When Serge came to the company, he asked how the last day was. One of the operators told him it was good, five parts. If he asked again days later, he got the answer that the number of parts was 300, which was also good. He is trying to get in some transparency visibility, to understand the reasons why a process is working or not. If they cannot deliver the operators tell sometimes, the machine is running at full capacity. It is difficult to assess whether this is 20,25 , or $70 \%$.

Serge makes himself unpopular with some of his actions and regulations. There is a customer to satisfy, he says.

His approach to overcome reservation and distrust is visibility. $\mathrm{He}$ installed whiteboards where the machine operators themselves indicated performance, with the ability to compare between machines. For each machine and operator, a target to attain is set. If the target number is surpassed, this is marked with a green pen, if the achievement is less, this is indicated with a red pen. Shortcomings against the targets set must be reported. There was a dominance of red on the board.

One workplace showed an achievement of 199 against a target of 225, the deviation of 26 marked in red. The operator said he did not have the required number of parts. The parts arrived from quality control only at $10 \mathrm{am}$, due to some faulty process, he did not have any influence on that. There is a queue before quality control. With the shift starting at seven, and the parts arriving at 10 , these are three lost hours of production, more than $30 \%$ of the shift time. Considering that the deviation in the number of parts was only minus $20 \%$, the shift could have been one with good productivity.

There is a large amount of waste involved in many of the processes, delays, faults, non-value-added activities. Analyzing an order with a 
throughput time of 20 days, you might find it took 8 days just in administration. This is an opportunity to improve. People are aware of that, they know what is working, and what is not. Inertness is stronger than the willingness to change, though.

Workers spend much time searching for parts or tools, sometimes hours. This greatly reduces productivity. One worker is proud of walking several kilometers in one day.

Machines need to be effectively maintained to reduce standstill. These are a major cause for high costs and a loss of capacity, often resulting in delayed completion of customer orders, therefore, another type of waste.

We are now in the second shift. A worker is grinding bars. At the machine, one signal light is red. The operator is supposed to pay attention and act accordingly. He is too much occupied with what he is doing presently. Some machines are running, are not stopped even if there are no parts to be worked on. Much energy is wasted. All the lights are on, there are no energy-saving lamps.

It is not an easy task to find people with the right qualification. Some of them have grown to be highly proficient over the years. They are experienced, they know from the noise and the smell of whether the machine is working properly or not. Now they are losing this capability because they are wearing ear protection. They do not have that feeling anymore. Young people are coming in, they do not have that experience. There are efforts to attract people from technical schools, from colleges, but it is difficult to find qualified people.

So how can Industry 4.0 contribute? End-to-end data integration and networked automation can make operations more effective. Problems can be identified before they become apparent, before some tool breaks. Causes can be analyzed, and potential action suggested, or even taken autonomously. Industry 4.0 should foresee problems, preventive action.

In conclusion, much productive time is wasted or spent on firefighting. Smart technology and data integration are enablers for better visibility and more productive use of valuable resources. Human factors must be considered, though. Resistance and inertness in people are major barriers to achieving improvements. 


\subsection{Conclusions and Outlook}

Industry 4.0 offers various benefits to the human factor, including a reduction of physical efforts, improved decision-making based on defined criteria, more efficient internal and external communication, and the effective usage of tools and data.

However, the establishment of an adequate teaching and learning culture must be considered a prerequisite in the process of digital transformation on the level of the employees and on the level of top management, as well. Within professional education processes, adapted learning conditions and learning environments must be established to create a foundation for successful learning paths.

Moreover, the communication patterns within the company must be regarded as an essential success factor toward the implementation of a new, respectively, of a realigned learning culture. Without trust and commitment on the individual level, but also in groups of companies, no professional learning processes can be realized. Accordingly, companies must be sensitized in terms of both determinants that promote learning and determinants that inhibit learning by focusing on the realignment toward either functional, extensional, or intentional forms of learning and communication or even a combination of them in business organizations.

Problems on the shop floor are often man-made, or organization induced. So, technology is not a solution for itself, implementation must be planned for in a human-centered manner. Human work will continue to be required in Industry 4.0 environments, both for the development of this concept as the management of advanced production systems, and the application of technologies and tools. Change processes necessitate interventions and actions in cognitive, emotional, and psychic aspects (Silva et al. 2019). Adequate conditions and environments for human work must be ensured. Information, motivation, and empowerment of people are critical factors for the effective and efficient introduction of smart industry solutions.

Acknowledgements This research is part of the project 'SME 4.0 - Industry 4.0 for SMEs', which has received funding from the European Union's Horizon 
2020 research and innovation program under the Marie Skłodowska-Curie grant agreement No. 734713.

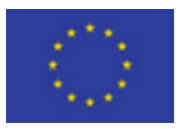

\section{References}

Beham, A., S. Raggl, V.A. Hauder, J. Karder, S. Wagner, and M. Affenzeller. 2020. Performance, quality, and control in steel logistics 4.0. Procedia Manufacturing 42: 429-433. https://doi.org/10.1016/j.promfg.2020.02.053.

bitkom. 2020a. Digitalisierung der Logistik. https://www.bitkom.org/sites/def ault/files/2019-06/bitkom-charts_digitalisierung_der_logistik_03_06_2019. pdf. Accessed on 10 December 2020.

bitkom. 2020b. Digitalisierung macht Logistik schneller, sicherer und einfacher. https://www.bitkom.org/Presse/Presseinformation/Digitalisier ung-macht-Logistik-schneller-sicherer-und-einfacher. Accessed on 10 December 2020.

bitkom. 2020c. Industrie 4.0—so digital sind Deutschlands Fabriken. https:// www.bitkom.org/sites/default/files/2020-05/200519_bitkomprasentation_ industrie40_2020_final.pdf. Accessed on 10 December 2020.

Cimini, C., A. Lagorio, F. Pirola, and R. Pinto. 2020. How human factors affect operators' task evolution in logistics 4.0. Human Factors and Ergonomics in Manufacturing \& Service Industries: 1-20. https://doi.org/10. 1002/hfm.20872.

Creditreform. 2019. Digitalisierung und Wirtschaft 4.0. https://www.creditref orm.at/nc/news/news/news-list/details/news-detail/digitalisierung-und-wir tschaft-407404.html. Accessed on 10 December 2020.

Črešnar, R., V. Potočan, and Z. Nedelko. 2020. Speeding up the implementation of Industry 4.0 with management tools: Empirical investigations in manufacturing organizations. Sensors 20 (12): 1-25. https://doi.org/10. $3390 / s 20123469$. 
Dallasega, P., M. Woschank, S. Ramingwong, K.Y. Tippayawong, and N. Chonsawat. 2019. Field study to identify requirements for smart logistics of European, US and Asian SMEs. Proceedings of the 9th International Conference on Industrial Engineering and Operations Management (IEOM), Bangkok 2019, 844-855.

Dallasega, P., M. Woschank, H.E. Zsifkovits, K.Y. Tippayawong, and C.A. Brown. 2020. Requirement analysis for the design of smart logistics in SMEs. In Industry 4.0 for SMEs, ed. D.T. Matt, V. Modrák, H.E. Zsifkovits, 147-162. Cham: Palgrave Macmillan.

Delfmann, W., M. ten Hompel, and W. Kersten. 2018. Logistics as a scienceCentral research questions in the era of the fourth industrial revolution, 9th ed. Berlin: BVL.

Dengler, K., and Britta Matthes. 2015. Folgen der Digitalisierung für die Arbeitswelt. Substituierbarkeitspotenziale. https://doku.iab.de/forschungsbe richt/2015/fb1115.pdf. Accessed on 10 December 2020.

Eggers, H. 2007. Autonomes Lernen im Englischunterricht an der Grundschule. München: Grin.

Franz, J. 2016. Kulturen des Lehrens. Eine Studie zu kollektiven Lehrorientierungen in Organisationen Allgemeiner Erwachsenenbildung. Bielefeld: Bertelsmann.

Fraunhofer IIS. 2017. Transportlogistik 4.0. https://www.scs.fraunhofer.de/con tent/dam/scs/de/dokumente/studien/Transportlogistik.pdf. Accessed on 10 December 2020.

Geller, B. M. 1996. Individuelle, institutionelle und metaorganisatorische Lernprozesse als konstituierende Elemente des ganzheitlichen organisatorischen Lernens. Eine modelltheoretische Analyse. Linz: Trauner.

Haefner, K. 1980. Bildungspolitische und bildungskulturelle Konsequenzen autonomen Lernens. In Individuelles Lernen und Studieren, ed. H.-E. Piepho and G. Bauer, 120-149. Alsbach: Zebisch.

Hobscheidt, D., A. Kühn, and R. Dumitrescu. 2020. Development of riskoptimized implementation paths for Industry 4.0 based on socio-technical pattern. Procedia CIRP 91: 832-837. https://doi.org/10.1016/j.procir.2020. 02.242 .

Hodel, M., and H. Geißler. 1998. Organisationales Lernen und Qualitätsmanagement. Eine Fallstudie zur Erarbeitung und Implementation eines visualisierten Qualitätsleitbildes. Frankfurt: Lang.

Hof, C. 2013. Übergänge und Lebenslanges Lernen. In Handbuch Übergänge, ed. W. Schröer, B. Stauber, A. Walther, L. Böhnisch, and K. Lenz, 394-415. Weinheim: Beltz Juventa. 
Matt, D.T., V. Modrák, and H.E. Zsifkovits, eds. 2020. Industry 4.0 for SMEs. Cham: Palgrave Macmillan.

Miller, M. 1986. Kollektive Lernprozesse. Studien zur Grundlegung einer soziologischen Lerntheorie. Frankfurt: Suhrkamp.

Probst, G.J.B., and H. Naujoks. 1993. Autonomie und Lernen im entwicklungsorientierten Management. Zeitschrift für Organisation 6: 368-374.

Schmidtke, N., F. Behrendt, L. Thater, and S. Meixner. 2018. Technical potentials and challenges within internal logistics 4.0. Proceedings of the 4th IEEE International Conference on Logistics Operations Management, 1-10. https://doi.org/10.1109/GOL.2018.8378072.

Silva, V.L., J.L. Kovaleski, R.N. Pagani, A. Corsi, and M.A.S. Gomes. 2019. Human factor in smart industry: A literature review. Future Studies Research Journal: Trends and Strategies 12 (1): 87-111. https://doi.org/10.24023/Fut ureJournal/2175-5825/2020.v12i1.473.

Statista.de. 2020. Wie bewerten Sie die Relevanz von Digitalisierung der Wertschöpfungskette für Ihr Unternehmen? https://de.statista.com/progno sen/943099/expertenbefragung-zur-digitalisierung-in-der-logistikbranchein-deutschland. Accessed on 10 December 2020.

Tran-Dang, H., N. Krommenacker, P. Charpentier, and D.-S. Kim. 2020. The Internet of Things for logistics: Perspectives, application review, and challenges. IETE Technical Review: 1-29. https://doi.org/10.1080/02564602. 2020.1827308.

Treml, A.K. 2000. Allgemeine Pädagogik. Grundlagen, Handlungsfelder und Perspektiven der Erziehung. Stuttgart: Kohlhammer.

Ullrich, C., A. Hauser-Ditz, N. Kreggenfeld, C. Prinz, and Igel Christoph. 2018. Assistenz und Wissensvermittlung am Beispiel von Montage und Instandhaltungstätigkeiten. In Zukunft der Arbeit - eine praxisnahe Betrachtung, ed. S. Wischmann and E.A. Hartmann, 107-123. Berlin: Springer Vieweg.

Vuksanović Herceg, I., V. Kuč, V.M. Mijušković, and T. Herceg. 2020. Challenges and driving forces for Industry 4.0 implementation. Sustainability 12 (10): 1-22. https://doi.org/10.3390/su12104208.

Winkelhaus, S., and E.H. Grosse. 2020. Logistics 4.0: A systematic review towards a new logistics system. International Journal of Production Research 58 (1): 18-43. https://doi.org/10.1080/00207543.2019.1612964.

Wirtschaftskammer Österreich. 2019. Digitale Transformation von KMUs in Österreich 2019. Erfassung des Digialisierungsindex 2019. https:// www.wko.at/branchen/information-consulting/unternehmensberatung-buc hhaltung-informationstechnologie/kmu-digitalisierungsstudie-2019.pdf. Accessed on 10 December 2020. 
Woschank, M., and C. Pacher. 2020a. A holistic didactical approach for industrial logistics engineering education in the LOGILAB at the Montanuniversitaet Leoben. Procedia Manufacturing 51: 1814-1818. https://doi. org/10.1016/j.promfg.2020.10.252.

Woschank, M., and C. Pacher. 2020b. Fostering transformative learning processes in industrial engineering education. Proceedings of the 5th NA International Conference on Industrial Engineering and Operations Management (IEOM), Detroit 2020, 2022-2029.

Woschank, M., and C. Pacher. 2020c. Program planning in the context of industrial logistics engineering education. Procedia Manufacturing 51: 1819-1824. https://doi.org/10.1016/j.promfg.2020.10.253.

Woschank, M., and C. Pacher. 2020d. Teaching and learning methods in the context of industrial logistics engineering education. Procedia Manufacturing 51: 1709-1716. https://doi.org/10.1016/j.promfg.2020.10.238.

Woschank, M., and H.E. Zsifkovits. 2021. Smart logistics-Conceptualization and empirical evidence. Chiang Mai University Journal of Natural Sciences 20 (2): 1-9.

Woschank, M., E. Del Rio, H.E. Zsifkovits, and P. Dallasega. 2020a. Comparison of Industry 4.0 requirements between Central-European and SouthEast-Asian enterprises. Proceedings of the 5th NA International Conference on Industrial Engineering and Operations Management (IEOM), Detroit 2020. 2013-2021.

Woschank, M., E. Rauch, and H.E. Zsifkovits. 2020b. A review of further directions for artificial intelligence, machine learning, and deep learning in smart logistics. Sustainability 12 (9): 1-23. https://doi.org/10.3390/su1209 3760 .

Wrobel-Lachowska, M., A. Polak-Sopinska, and Z. Wisniewski. 2019. Challenges for logistics education in Industry 4.0. In Advances in human factors in training, education, and learning sciences, ed. S. Nazir, A.-M. Teperi, A. Polak-Sopińska, 329-336. Cham: Springer.

Zehnder, H. 2014. Betriebliche Bildung. Zwischen Wahrnehmungsverzerrung und Lernresistenz; was optische Täuschungen über das Lernen verraten. Berlin: Springer Gabler.

Zsifkovits, H., and M. Woschank. 2019. Smart Logistics - Technologiekonzepte und Potentiale. Berg-Und Hüttenmännische Monatshefte (BHM) 164 (1): 42-45. https://doi.org/10.1007/s00501-018-0806-9. 
Open Access This chapter is licensed under the terms of the Creative Commons Attribution 4.0 International License (http://creativecommons.org/ licenses/by/4.0/), which permits use, sharing, adaptation, distribution and reproduction in any medium or format, as long as you give appropriate credit to the original author(s) and the source, provide a link to the Creative Commons license and indicate if changes were made.

The images or other third party material in this chapter are included in the chapter's Creative Commons license, unless indicated otherwise in a credit line to the material. If material is not included in the chapter's Creative Commons license and your intended use is not permitted by statutory regulation or exceeds the permitted use, you will need to obtain permission directly from the copyright holder.

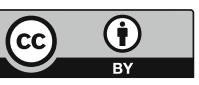

